\title{
Biofilm formation and virulence expression by Streptococcus mutans are altered when grown in dual-species model
}

\author{
Zezhang T Wen*1, David Yates², Sang-Joon Ahn² and Robert A Burne²
}

\begin{abstract}
Background: Microbial cell-cell interactions in the oral flora are believed to play an integral role in the development of dental plaque and ultimately, its pathogenicity. The effects of other species of oral bacteria on biofilm formation and virulence gene expression by Streptococcus mutans, the primary etiologic agent of dental caries, were evaluated using a dual-species biofilm model and RealTime-PCR analysis.

Results: As compared to mono-species biofilms, biofilm formation by $S$. mutans was significantly decreased when grown with Streptococcus sanguinis, but was modestly increased when co-cultivated with Lactobacillus casei. Cocultivation with S. mutans significantly enhanced biofilm formation by Streptococcus oralis and L. casei, as compared to the respective mono-species biofilms. RealTime-PCR analysis showed that expression of spaP (for multi-functional adhesin SpaP, a surface-associated protein that $S$. mutans uses to bind to the tooth surface in the absence of sucrose), gtfB (for glucosyltransferase B that synthesizes a1,6-linked glucan polymers from sucrose and starch carbohydrates) and $g b p B$ (for surface-associated protein $\mathrm{GbpB}$, which binds to the glucan polymers) was decreased significantly when $S$. mutans were co-cultivated with $L$. casei. Similar results were also found with expression of spaP and gbpB, but not gtfB, when S. mutans was grown in biofilms with S. oralis. Compared to mono-species biofilms, the expression of luxS in $S$. mutans co-cultivated with $S$. oralis or L. casei was also significantly decreased. No significant differences were observed in expression of the selected genes when S. mutans was co-cultivated with S. sanguinis.
\end{abstract}

Conclusions: These results suggest that the presence of specific oral bacteria differentially affects biofilm formation and virulence gene expression by S. mutans.

\section{Background}

Oral biofilms are compositionally and structurally complex bacterial communities. To date, more than 750 different species or phylotypes of bacteria have been identified in mature dental plaque [1]. Microbial cell-cell interactions in the oral flora and their impact on bacterial adherence and biofilm formation are beginning to be appreciated [1-4]. Cross-feeding or metabolic cooperation is well-documented among certain bacterial species in the oral flora. Veillonellae can utilize the lactic acid produced by streptococci and Porphyromonas gingivalis

* Correspondence: zwen@lsuhsc.edu

${ }^{1}$ Department of Oral and Craniofacial Biology and Department of

Microbiology, Immunology and Parasitology, Louisiana State University Health Sciences Center, New Orleans, LA 70119, USA

Full list of author information is available at the end of the article benefits from succinate produced by $T$. denticola. Similarly, isobutyrate secreted by $P$. ginivalis stimulates the growth of $T$. denticola [2,3]. Adhesin-ligand mediated physical interactions such as those between Streptococcus gordonii and $P$. gingivalis may be important for secondary colonizers like $P$. gingivalis to establish and persist in the oral cavity [5]. A recent study has also provided evidence that a mutualistic effect in biofilm formation between Actinomyces naeslundii and Streptococcus oralis is facilitated by autoinducer-2 (AI-2) [6]. Intra- and inter-species interactions are believed to play a crucial role in community dynamics, contributing to the formation of plaque and, ultimately, the development of polymicrobial diseases, including caries and periodontitis [2,5]. Therefore, a better understanding of cell-cell interactions between oral pathogens and commensal bacteria, and the impact 
of these interactions on expression of virulence factors and pathogenicity, could lead to development of novel preventive and therapeutic strategies against dental caries and periodontitis.

As the principal etiological agent of human dental caries, Streptococcus mutans has developed multiple mechanisms to colonize the tooth surface and, under certain conditions, to become a numerically significant species in cariogenic biofilms [7]. The multi-functional adhesin SpaP, also called P1 and PAc1, is considered the primary factor mediating early attachment of $S$. mutans to tooth enamel in the absence of sucrose [8]. S. mutans also produces at least three glucosyltransferases (GtfB, -C \& -D), which polymerize the glucosyl moiety from sucrose and starch carbohydrates into $\alpha 1,3$ - and $\alpha 1,6$-linked glucans $[7,9]$. Binding to glucans by glucan binding proteins (GbpA, -B, -C and -D) and by the Gtfs facilitates bacterial adherence to tooth surfaces, inter-bacterial adhesion and accumulation of biofilms [9,10]. GtfBC\&D and GbpABC\&D, together with the adhesive extracellular glucans, constitute the sucrose-dependent pathway for $S$. mutans to establish on the tooth surface and are of central importance in plaque formation and development of caries [7,9-14].

Multiple regulatory networks that integrate external signals, including the cell density-dependent Com system and other two-component regulatory systems, including CiaHR, LiaSR and VicRK, with CiaH, LiaS and VicK being the sensor kinases and CiaR, LiaR and VicR the response regulators of two-component system, are required for biofilm formation [15-21]. S. mutans also possesses a LuxS-mediated signaling pathway that affects biofilm formation and bacteriocin production $[18,22,23]$. LuxS is the enzyme that catalyzes the reactions leading to the production of the AI-2 signal molecule [24]. In addition, a number of other gene products, such as BrpA (a cell surface-associated biofilm regulatory protein), have also been shown to play critical roles in environmental stress responses and biofilm development by $S$. mutans $[25,26]$. While much effort has been devoted to understanding the molecular mechanisms of adherence, biofilm development and virulence gene expression by $S$. mutans in pure cultures, there are large gaps in our knowledge of how this cariogenic bacterium behaves in response to inter-generic interactions with bacteria commonly found in the supragingival plaque.

In this study, we developed a dual-species in vitro model to examine the impact of co-cultivation of $S$. mutans with $S$. oralis or S. sanguinis, two primary colonizers and members of the normal flora, or with Lactobacillus casei, a bacterium frequently isolated from carious sites, on biofilm formation by these bacteria and expression of known virulence factors of $S$. mutans. Data presented here suggest that growth in dual-species impacts surface biomass accumulation by some of the bacterial species analyzed, as compared to the respective monospecies biofilms and that the expression of known virulence factors by $S$. mutans can be differentially modulated by growth with other bacteria commonly found in dental plaque. Such interactions may influence the formation, architecture and pathogenic potential of human dental plaque.

\section{Methods}

\section{Bacterial strains and growth conditions}

S. mutans UA159, S. oralis SK92 and S. sanguinis SK150 were maintained in Brain Heart Infusion (BHI, Becton, Dickinson and Company, MD), and L. casei 4646 was maintained in Lactobacillus MRS (Difco Laboratories, MI). For biofilm formation, all cultures were grown on semi-defined biofilm medium (BM) [27] with $18 \mathrm{mM}$ glucose and $2 \mathrm{mM}$ sucrose as the supplemental carbohydrate sources (BMGS) $[18,26]$. Biofilms were grown in a $5 \%$ $\mathrm{CO}_{2}$-aerobic atmosphere at $37^{\circ} \mathrm{C}$. For growth studies using a Bioscreen $\mathrm{C}$ (Oy Growth Curves AB Ltd, Finland), cultures were grown at $37^{\circ} \mathrm{C}$ aerobically and the optical densities were monitored every 30 minutes, with shaking for 10 seconds before measurement [28].

\section{Growth of dual-species biofilms}

Sterile glass slides were used as substratum and biofilms were grown by following a protocol described previously $[25,26]$. Briefly, overnight broth cultures were transferred by 1:50 dilutions into fresh, pre-warmed, broth medium (BHI for streptococci and MRS for lactobacillus) and were allowed to grow until mid-exponential phase $\left(\mathrm{OD}_{600}\right.$ $\mathrm{nm}$ 0.5) before transfer to BMGS for biofilm formation. For mono-species biofilms, $450 \mu \mathrm{l}$ of the individual cultures was added to the culture tube, and for two-species biofilms, $450 \mu \mathrm{l}$ of each culture was used as inoculum. The biofilms grown on the glass slides that were deposited in $50 \mathrm{ml}$ Falcon tubes were aseptically transferred daily to fresh BMGS. After four days, the biofilms were scratched off with a sterile spatula and suspended in 7.5 $\mathrm{ml}$ of $10 \mathrm{mM}$ potassium phosphate buffer, $\mathrm{pH}$ 7.0. To dechain and separate the cells, the biofilms were sonicated using a Sonic Dismembrator (model 100, Fisher Scientific, Idaho) at energy level 3 for 25 seconds, twice, with 2 minutes on ice between treatments. To determine the total number of viable bacterial cells (colony-forming units, CFU), $100 \mu \mathrm{l}$ from dispersed, four-day biofilms was serially diluted in potassium phosphate buffer, $10 \mathrm{mM}$, $\mathrm{pH} 7.0$, and plated in triplicate on BHI agar plates.

\section{RNA extraction}

Immediately after sampling for plating, bacterial cells were treated with RNAProtect (Qiagen Inc., CA) as recommended by the supplier. The cells were then pelleted 
by centrifugation and total RNA extractions were performed using a hot phenol method $[18,26]$. To remove all DNA, the purified RNAs were treated with DNAse I (Ambion, Inc., TX) and RNA was retrieved with the Qiagen RNeasy purification kit, including an additional oncolumn DNAse I treatment with RNase-free DNase I.

\section{RealTime-PCR}

For RealTime-PCR, gene-specific primers were designed using the DNA mfold program http://mfold.bioinfo.rpi.edu/cgi-bin/dna-form1.cgi and Beacon Designer 3.0 (PREMIER Biosoft International, Palo Alto, CA) using the following criteria: primer length 20-22 nucleotides, $\mathrm{T}_{\mathrm{m}} \geq 60^{\circ} \mathrm{C}$ with $50 \mathrm{mM} \mathrm{NaCl}$ and $3 \mathrm{mM} \mathrm{MgCl}$, and the expected length of PCR products $85-150 \mathrm{bp}$ (Table 1). For RealTime-PCR, cDNA was generated with gene-specific primers using SuperScript III First Strand Synthesis Kit (InVitorgen, CA) by following the supplier's recommendations. For validation assays, iScript Reverse Transcriptase was also used to generate cDNA templates with random nanomers as primers (Bio-Rad laboratories, CA). RealTime-PCR was conducted using the iCycler iQ real time PCR detection system (Bio-Rad Laboratories), with controls and standards as described previously $[20,26]$.

\section{Data analysis}

The mRNA copy number of selected virulence factors was determined per $\mu \mathrm{g}$ of total RNA. When grown in the dual-species model, the values were further normalized to relative numbers of $S$. mutans by multiplying the copy number by the ratio of $S$. mutans CFU to the total CFU in the mixed-species biofilms. The resulting data were expressed as copy number per $\mu \mathrm{g}$ of $S$. mutans total RNA.
Statistical analysis was carried out using the non-parametric Kruskal-Wallis test and $t$-test.

\section{Results and Discussion}

Establishment of a suitable biofilm model for the reliable monitoring of gene expression in S. mutans

Glass slides can be used very effectively to cultivate biofilms of oral bacteria [26,29]. As compared to tooth enamel model systems, e.g. hydroxylapatite disks, glass slides are easier to handle, stable and non-reactive. By daily transfer to fresh medium, bacteria on glass surfaces continue to accumulate and generate sufficient biofilms after 3-4 days for multiple experiments [29], including whole genome transcriptional profiling [26].

For measurement of the expression levels of selected virulence factors by $S$. mutans, total RNA was extracted from mono- and dual-species biofilms and RealTimePCR reactions were carried out using gene-specific primers (Table 1). To confirm that no genomic DNAs left in the RNA preps, cDNA synthesis reactions that received no reverse transcriptase were used as controls and results of RealTime-PCR using gene-specific primers (Table 1) showed that none of the RNA preps used in this study had any significant genomic DNA contamination. To verify that the primers did not amplify non-S. mutans genes under the conditions tested, total RNA of S. oralis, S. sanguinis and $L$. casei, either alone or in mixtures with known quantities of $S$. mutans RNA, were used as a template for reverse transcription and RealTime-PCR. No cDNA was detected when S. oralis, S. sanguinis or L. casei total RNA alone was used as a template with primers for $s p a P, g t f B, g b p B$, luxS, and $b r p A$, as well as the $l d h$ gene encoding lactate dehydrogenase) (data not shown). Melt-

Table 1: Primers used for RealTime-PCR

\begin{tabular}{|c|c|c|c|}
\hline Primer & DNA sequence (5' T 3') & Application & Amplicon \\
\hline spaP-Fw & TCCGCTTATACAGGTCAAGTTG & spaP fragment & $121 \mathrm{bp}$ \\
\hline spaP-Rv & GAGAAGCTACTGATAGAAGGGC & & \\
\hline gtfB-Fw & AGCAATGCAGCCATCTACAAAT & gtfB fragment & $98 \mathrm{bp}$ \\
\hline gtfB-Rv & ACGAACTTTGCCGTTATTGTCA & & \\
\hline gbpB-Fw & CGTGTTTCGGCTATTCGTGAAG & $g b p B$ fragment & $108 \mathrm{bp}$ \\
\hline gbpB-Rv & TGCTGCTTGATITTCTTGTTGC & & \\
\hline luxS-Fw & ACTGTTCCCCTITTGGCTGTC & luxS fragment & $93 \mathrm{bp}$ \\
\hline luxS-Rv & AACTTGCTTTGATGACTGTGGC & & \\
\hline brpA-Fw & CGTGAGGTCATCAGCAAGGTC & brpA fragment & $148 \mathrm{bp}$ \\
\hline brpA-Rv & CGCTGTACCCCAAAAGTTTAGG & & \\
\hline Idh-Fw & TTGGCGACGCTCTTGATCTTAG & Idh fragment & $92 \mathrm{bp}$ \\
\hline Idh-Rv & GTCAGCATCCGCACAGTCTTC & & \\
\hline
\end{tabular}


ing curves consistently presented unique amplification products for every amplicon tested. Results also demonstrated that the presence of RNA from non-mutans streptococci or from lactobacilli had no significant effect on the efficiency of amplification of S. mutans specific products. Specifically, quantification of the respective genes in mixed RNA samples yielded results that were proportional to the amount of $S$. mutans RNA used in the reactions (data not shown). Similar results were also obtained with genomic DNA from the respective strains as templates (data not shown).

The choice of appropriate controls for this study was carefully considered. Ribosomal RNA is the most commonly used reference in single species transcriptional analysis, and has often been used as a control in Northern analysis of $S$. mutans RNA [18,30]. However, use of ribosomal RNAs could be misleading when it is used for analysis of gene expression in mixed-species biofilms, especially when closely related species are present in the consortium. Specifically, during calibration of the methods, cross-reactions between rRNA of different bacterial sources were noted, as shown by multiple peaks in the melting curves in the RealTime-PCR reactions (data not shown). Therefore, rather than use rRNA total viable counts (CFU) were used to normalize the RealTime-PCR data. Brief sonication was used to disperse the biofilms. When plated on BHI agar plates, the distinctive colony morphology of S. mutans (flat, opaque, dry colonies with rough surface) versus $S$. oralis (small, flat and smooth colonies), S. sanguinis and L. casei (both forming small, wet, convex colonies with shiny and smooth surfaces) made it easy to distinguish $S$. mutans from the other streptococci and $L$. casei. For S. mutans-L. casei dual-species biofilms, an erythromycin resistant $L$. casei strain (Browngardt and Burne, unpublished data) was also used in dual-species biofilms, and BHI agar plates containing erythromycin (5 $\mu \mathrm{g} \mathrm{ml}^{-1}$ ) were used for viable counts of $L$. casei. The results were similar to those when $\mathrm{BHI}$ agar plates were used (data not shown).

The lactate dehydrogenase gene $l d h$ of $S$. mutans has been reported to be constitutively expressed [31] (Wen and Burne, unpublished data), so we also examined whether this gene may serve as a suitable reference. No cross-reactions were detected between primers of $S$. mutans $l d h$ and genes of other bacteria (data not shown). As expected, no significant difference in expression of $l d h$ was observed between $S$. mutans grown in mono-species biofilms and those in dual-species biofilms, following proper normalization to CFU (Figure 1). Similar results were obtained when random primers were used to generate cDNA template instead of $l d h$-specific primers. These results add additional support to the finding that RealTime-PCR with normalization to CFU is a reliable

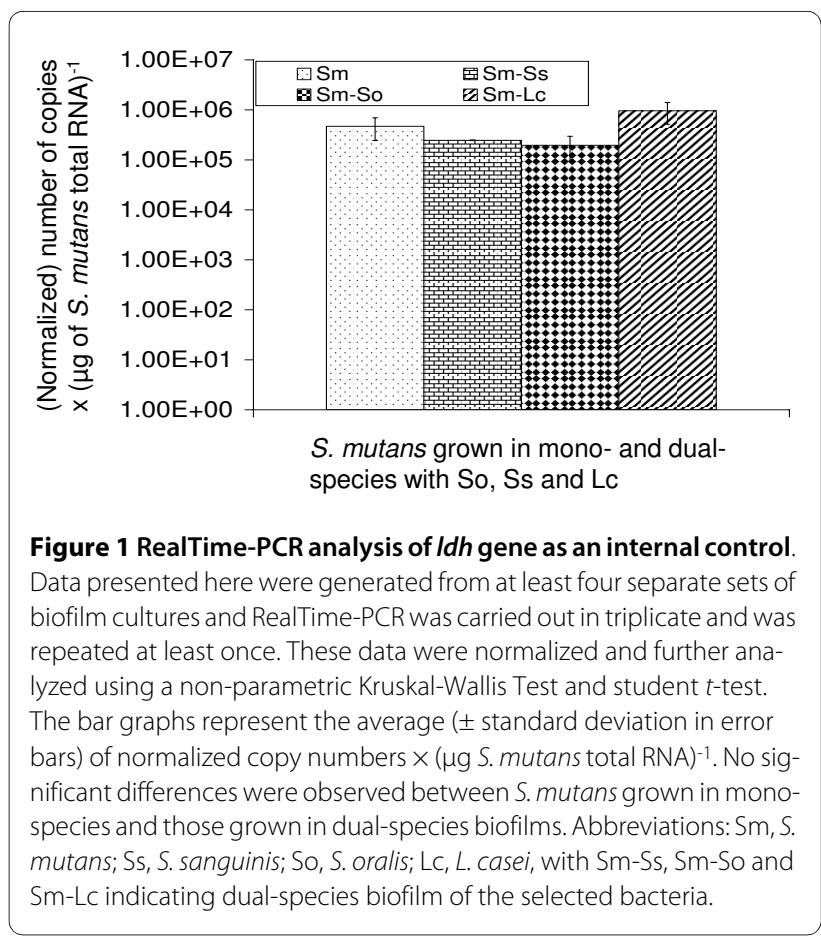

approach for assessment of gene regulation in S. mutans growing in this mixed-species biofilm model.

\section{S. mutans enhances biofilm formation by S. oralis and $\mathrm{L}$. casei in dual-species model}

When grown on glass slides, $S$. mutans accumulated an average of $8.8 \times 10^{10} \mathrm{CFU}$ after 4 days (Figure 2). S. sanguinis also formed biofilms efficiently on glass surfaces, averaging $8.2 \times 10^{10} \mathrm{CFU}$ after 4 days. When these two bacteria were grown in the dual-species model, the level

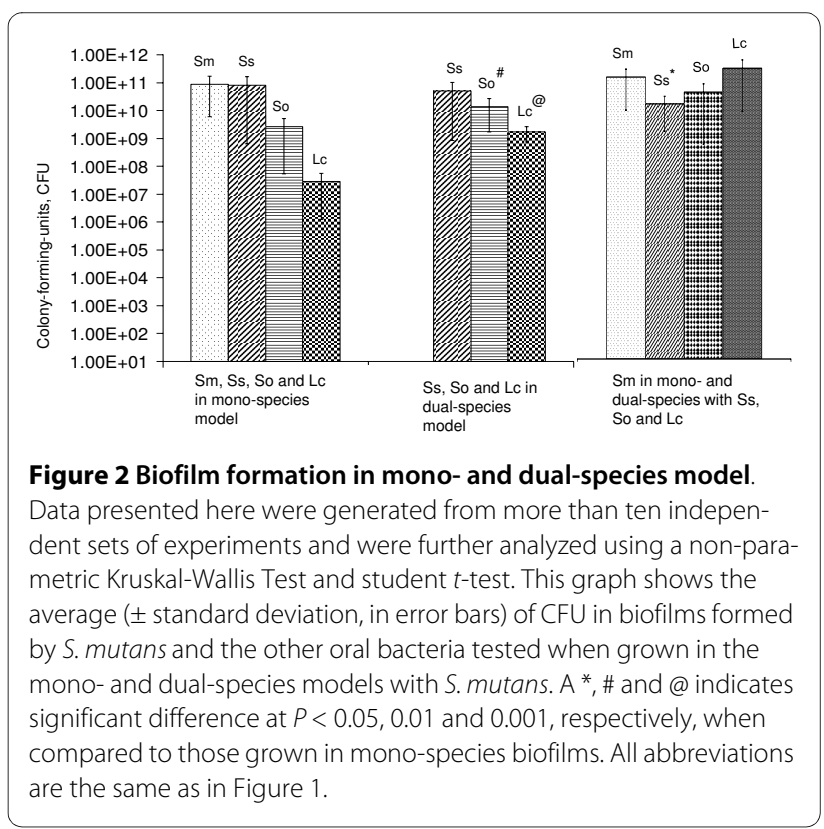


of $S$. mutans decreased by more than 8 -fold $(P<0.05)$, yielding an average of $1.0 \times 10^{10} \mathrm{CFU}$, while $S$. sanguinis accumulated to $5.1 \times 10^{10} \mathrm{CFU}$. $S$. oralis displayed a relatively poor capacity to form biofilms when grown alone, averaging $2.6 \times 10^{9} \mathrm{CFU}$ after 4 days. When grown in dual-species with $S$. mutans, however, the number of $S$. oralis in the biofilms increased to an average of $1.4 \times 10^{10}$ CFU $(P<0.01)$. On the other hand, biofilm formation by $S$. mutans was decreased when grown together with $S$. oralis, although the difference between mono-species and dual-species was not statistically significant. L. casei alone formed biofilms poorly, accumulating only $2.9 \times$ $10^{7} \mathrm{CFU}$ after 4 days. However, the capacity of $L$. casei to form biofilms was enhanced significantly $(P<0.001)$ when co-cultivated with $S$. mutans, resulting in an increase of more than 60-fold to an average of $1.7 \times 10^{9}$ CFU after 4 days. Notably, when S. mutans was cultivated in dual-species biofilms with $L$. casei, the organisms accumulated in about 2-fold greater numbers than when $S$. mutans was grown alone, averaging $1.8 \times 10^{11} \mathrm{CFU}$.

Various bacterial cell-cell interactions may exist when growing in dual-species biofilms, including competition for binding sites and nutrients available. In this study, the same amount of inoculum was used in mono- and dualspecies biofilms. For bacteria that grow similarly well in mono-species model, slight decreases will be expected for both constituents when grown in dual-species biofilms. The observed decreases in population of both S. mutans and S. sanguinis when they were cultivated together (Figure 2), as compared to the respective mono-species biofilms, could be at least in part attributed to competition for binding sites. Both S. sanguinis and S. oralis grew well in BMGS broth, with a doubling time of $86.5( \pm 2.7)$ and 80 ( \pm 6.1$)$ minutes, respectively, whereas $S$. mutans took 134.7 ( \pm 11.6) minutes to double its optical density. These results suggest that $S$. sanguinis and S. oralis should possess advantages over $S$. mutans for available nutrients when grown in a mixed-species consortium. Disadvantages in nutrient competition could certainly affect the capacity of $S$. mutans to accumulate on the glass surfaces, contributing to the observed decreases in biofilm formation when grown together with S. sanguinis or S. oralis (Figure 2). S. sanguinis is also known to produce hydrogen peroxide, which can inhibit the growth of $S$. mutans $[4,32]$, although such an impact on S. mutans growth was shown to be limited when the organisms were inoculated simultaneously [32], as they were in this study.

L. casei did not grow well in BMGS broth, yielding an average of $4.7 \times 10^{7} \mathrm{CFU} \mathrm{ml}-1$ after 24 hours, as compared to $6.0 \times 10^{8} \mathrm{CFU} \mathrm{ml}-1$ for S. mutans. Poor growth could certainly contribute to poor biofilm formation by this bacterium. As was observed with dual-species biofilms, however, co-cultivation of $L$. casei and S. mutans planktonically in BMGS broth also increased $S$. mutans CFU by more than 3-fold, with an average CFU of $2.3 \times 10^{9} \mathrm{ml}^{-1}$, although the numbers of $L$. casei remained similar to those in mono-species cultures (data not shown). The mixed-species broth cultures also had a slightly decreased doubling time (121.4 \pm 8.8 minutes), as compared to $S$. mutans $(134.7 \pm 11.8$ minutes) and L. case $i$ (240 \pm 24 minutes) in mono-species planktonic cultures. BHI, and especially MRS, yielded much better growth of L. casei than BMGS, although no major differences were observed in biofilm formation by L. casei when grown in BHI or MRS (data not shown).

Oral lactobacilli, such as L. casei, are a group of acid tolerant bacteria that are commonly isolated in relatively significant proportions from cariogenic dental plaque [33-36]. However, the ability of lactobacilli to adhere to the tooth surface was known to be poor [36]. Results presented here also suggest that $L$. casei alone does not form biofilms on glass surfaces very effectively, but biofilm formation by this bacterium can be dramatically improved when mixed with S. mutans. S. mutans produces at least three Gtf enzymes [7] that produce high molecular weight glucans that promote bacterial adhesion and biofilm accumulation. Recent studies have shown that these enzymes, especially GtfB, are capable of directly binding to L. case $i$ and other oral bacteria [37]. Adsorption of Gtfs to the surface of non-mutans streptococci can promote adhesion of the bacteria via glucan-mediated pathways [37]. Thus, the Gtf enzymes of S. mutans and the adhesive glucans likely contribute to the enhanced biofilm formation by L. casei, and probably S. oralis, when grown in mixed-species biofilms with $S$. mutans. Notably, enhanced biofilm formation by Lactobacillus plantarum and Lactobacillus rhamnosus was noted in a mucin-based medium [38], so the presence of polysaccharides may have a general ability to promote biofilm formation by lactobacilli. However, the actual mechanism for the enhancement of $L$. casei levels in biofilms with $S$. mutans requires further investigation.

While the close association of L. casei and S. mutans in carious sites is well documented, little information is available concerning the interaction between these two bacteria with respect to $S$. mutans biofilm formation and its cariogenicity. While co-cultivation with S. mutans significantly enhanced biofilm formation by $L$. casei, the sessile population of $S$. mutans was also found to be increased by more than 2 -fold in dual species model with L. casei (Figure 2), which is contrary to what was observed with the other bacteria studied. While the exact nature and the underlying mechanism await further investigation, the interaction observed between $S$. 
mutans and L. casei may partly explain the prevalence and the close association of these two bacteria in cariogenic plaque.

\section{Expression of genes critical to cariogenicity of S. mutans can be altered when grown in mixed-species biofilms}

RealTime-PCR was used to analyze the expression of several genes that have critical roles in bacterial adherence and biofilm accumulation by $S$. mutans [7-10], including $s p a P, g t f B$ and $g b p B$. As shown in Figure 3, slight decreases were observed in expression of spaP, $g t f B$ and $g b p B$ by $S$. mutans when grown in dual-species with $S$. sanguinis as compared to those in mono-species biofilms, although the differences were not statistically significant. When grown in dual-species with $L$. casei, however, expression of spaP, $g b p B$ and $g t f B$ by $S$. mutans was decreased by as much as 40-fold, at a significance level of $P<0.05$ for spaP and $P<0.001$ for $g t f B$ and $g b p B$, respectively, as compared to cells in mono-species biofilms. The expression of $\operatorname{spaP}(P<0.05)$ and $g b p B(P<0.001)$, but not $g t f B$, was also lower by more than 30 -fold in $S$. mutans when grown with $S$. oralis. As compared to mono-species biofilms, expression of $\operatorname{luxS}$ was decreased by more than 7 -fold in cells grown with $L$. casei $(P<$ $0.001)$ and by more than 15 -fold in cells with $S$. oralis $(P<$ 0.001 ), but again no significant differences were observed when $S$. mutans was grown with $S$. sanguinis. Expression of $\operatorname{brp} A$ was decreased by more than 3 -fold $(P<0.05)$ in cells grown with $S$. oralis, but no major differences were observed when grown with S. sanguinis and L. casei. As a control, the expression of the ldh gene, a constitutively expressed gene (Wen and Burne, unpublished data) [4], was also analyzed and no significant differences were observed between $S$. mutans grown in single-species and those grown in dual-species (Figure 1).

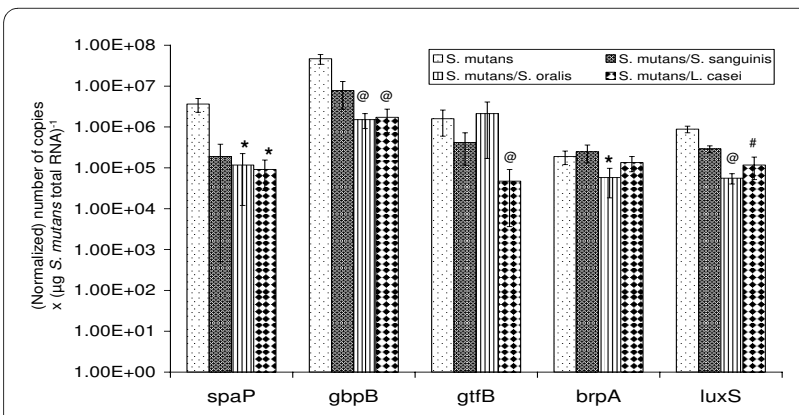

Figure 3 RealTime-PCR analysis of selected genes. RealTime-PCR for specific genes was carried out in triplicate and repeated at least once. Data presented here were generated from at least four independent sets of experiments. These data were normalized and further analyzed using a non-parametric Kruskal-Wallis Test and student $t$-test. The bar graphs represent the average ( \pm standard deviation in error bars) of copy numbers $\times$ ( $\mu \mathrm{g}$ S. mutans total RNA $)^{-1}$, with * * \# and @ illustrating statistical differences at $P<0.05,0.01$, and 0.001 , respectively, when compared to the respective genes in mono-species biofilms.
Glucosyltransferases and glucan-binding proteins of $S$. mutans are known to be differentially expressed in response to environmental conditions, such as carbohydrate source and availability, $\mathrm{pH}$ and growth of the bacteria on surfaces $[9,39-41]$. Results presented here further demonstrate that the level of expression of these known virulence attributes can be altered when $S$. mutans is grown in dual-species biofilms and that the effect varies as a function of the species of bacteria in the biofilms. Among the three different bacterial species analyzed, the most significant effect on the expression of the selected genes was seen with $L$. casei, followed by S. oralis. No significant effect was observed with $S$. sanguinis in expression of either spaP, $g t f B$ or $g b p B$. As described above, nutrient availability, especially when grown together with faster growing microorganisms, such as S. oralis, could have an impact on gene expression in S. mutans, and consequently affect biofilm formation [42].

L. casei, as a frequent isolate from the cariogenic plaque, is also known for its high capacity for acid production from carbohydrates. When grown on BMGS in mono-species cultures, S. mutans overnight (24-hour) cultures had an average $\mathrm{pH}$ of $5.75( \pm 0.28)$. As expected, the $\mathrm{pH}$ was decreased slightly when grown in dual species with $L$. casei, averaging 5.63( \pm 0.20$)$. Similar results were also observed when $S$. mutans was grown together with $S$. oralis, with an average $\mathrm{pH}$ measured at $5.69( \pm 0.08)$. In contrast, however, the $\mathrm{pH}$ of overnight cultures of $S$. mutans co-cultured with $S$. sanguinis was $5.95( \pm 0.03)$. Environmental $\mathrm{pH}$ has been shown to influence the expression of some of the genes selected [39]. Although not necessarily fully reflective of what occurs in sessile populations, the decreases in culture $\mathrm{pH}$ suggest that $S$. mutans may endure a more significant acid challenge when grown in dual-species with $L$. casei as well as S. oralis and that such decreases could at least in part contribute to the down-regulation of the selected genes in $S$. mutans grown in dual-species with $L$. casei and S. oralis.

Many bacteria produce autoinducer 2 through LuxS enzymes [43]. Recent studies of the oral flora have yielded evidence that AI-2 mediated signaling in the flora may play an important role in inter-species communication, affecting plaque formation and, ultimately, development of oral diseases $[6,23,44,45]$. Neither $S$. oralis nor $A$. naeslundii alone were found to form good biofilms, but growth in the two-species model resulted in abundant mutualistic growth [46]. AI-2 of S. oralis was recently found to be critical for such a mutualistic interaction [6]. Below and above the optimal concentration, mutualistic biofilm growth was suppressed. In S. mutans, LuxS was shown to be involved in biofilm formation and to affect the structure of biofilms [18,22,23], although its role in regulation of factors critical to bacterial adherence and biofilm formation is somewhat controversial. As shown 
previously, LuxS-deficiency significantly decreased $\operatorname{brp} A$ expression, but no major differences were seen between wild-type and the LuxS-deficient mutants in expression of $g t f B C, g b p B$ or spaP [18]. Similar results were also obtained by DNA microarray analysis in both planktonic [47] (Wen et al., unpublished data) and sessile populations (Wen et al., unpublished data). In a study using RealTime-PCR, however, Yoshida et al. [23] reported that transcription of $g t f B$ and $g t f C$, but not $g t f D$, was up-regulated in response to LuxS-deficiency. Like S. mutans and $S$. oralis, both $S$. sanguinis http://www.oralgen.lanl.gov and $L$. casei (Wen and Burne, unpublished data) possess LuxS. It remains unclear, however, whether LuxS in these bacteria is in fact involved in cell-cell communication. Nevertheless, down regulation of luxS expression in $S$. mutans when grown in dual-species with $L$. casei and $S$. oralis would likely affect the absolute concentration of AI-2 in the biofilms. Studies are ongoing to determine whether AI-2 signaling is functional between these bacterial species and whether alterations in $\operatorname{luxS}$ expression does in fact affect the expression of known virulence factors by $S$. mutans in mixed-species biofilms.

It is well established that GtfB and GbpB are critical components of the sucrose-dependent pathway in $S$. mutans biofilm formation and cariogenicity. In the presence of sucrose, GtfB synthesizes copious a1,3-linked, water insoluble glucan polymers. Then, surface-associated glucan-binding protein $\mathrm{GbpB}$ and others bind to these polymers, facilitating intercellular adherence and biofilm accumulation by $S$. mutans. It would be expected that down-regulation of GtfB and GbpB would result in less biofilm formation. Surprisingly, our S. mutans-L. casei dual-species data showed that $S$. mutans accumulated more than 2-fold more biofilms while the expression of $g t f B$ and $g b p B$ was decreased. One possible explanation is that down regulation of GtfB and GbpB (and probably some other members of the Gtfs and Gbps) when grown together with $L$. casei altered the balance of glucans to glucan-binding proteins ratio or altered the glucan structure in a way that altered biofilm architecture. In fact, similar observations have also been reported recently by us and some other groups $[11,12,48]$. In particular, deficiency of trigger factor (RopA) in S. mutans reduced production of GtfB and -D as revealed by Western blotting, but the rop $A$-mutant formed more than $50 \%$ more biofilms than the parental strain when sucrose was provided as the supplemental carbohydrate source [48]. During characterization of GbpA of S. mutans, the Banas group showed that strains deficient in GbpA were more adherent in vitro and more cariogenic in vivo than the parental strain $[11,12]$. As compared to the biofilms by the parent strain, which were composed of big cellular clusters with large gaps in between, the biofilms formed by the $g b p A$ - mutant were relatively small, but more com- pact and more evenly distributed. Interestingly, GbpAdeficiency was later found to increase the frequency of recombination between the tandemly arranged, highly homologous $g t f B$ and $g t f C$ genes, resulting in a dramatic decrease in production of water-insoluble glucans. Additional experiments that probe the basis for altered $g t f$ and $g b p$ expression, coupled with measurements of Gtf and Gbp protein and activity and glucan structure will be needed to shed light on the basis for the observations.

\section{Conclusions}

In vitro dual-species biofilm model and RealTime-PCR analysis showed that biofilm formation and virulence expression by $S$. mutans could be altered in response to the presence of other oral bacterial species. Effort is currently directed to further investigation of the underlying mechanism of the altered expression of selected genes and the impact of such alterations on biofilm formation by $S$. mutans. Considering the frequent association of $L$. case $i$ and $S$. mutans in carious sites and their role in caries development, information yielded from these studies could be used to formulate novel strategies against human dental caries.

\section{List of abbreviations}

AI-2: autoinducer 2; GtfB, -C \& -D: glucosyltransferase B, C \& D; GbpA, -B, -C, \& -D: glucan-binding protein A, B, $\mathrm{C} \& \mathrm{D}$; CFU: colony-forming-unities; BHI: brain heart infusion; MRS: lactobacilli MRS medium; SpaP: adhesin P1; BrpA: biofilm regulatory protein A; ldh: lactate dehydrogenase gene; BM: biofilm medium; BMG: BM plus glucose; BMS: BM plus sucrose; BMGS: BM plus glucose and sucrose.

\section{Authors' contributions}

ZTW conceived the study, designed and implemented most of the experiments, and drafted the manuscript; DY carried out most of the biofilm assays and RealTime-PCR analysis; SJA was involved in parts of experimental design and data analysis; RAB participated the experimental design and data analysis and revised critically the manuscript. All authors have read and approved the manuscript.

\section{Acknowledgements}

This work is supported by NIDCR grants DE13239 and 12236 to RAB and in part by DE15501 and DE19452 to ZTW. We thank Mr. Christopher Browngardt for his kind help with statistical analysis.

\section{Author Details}

'Department of Oral and Craniofacial Biology and Department of Microbiology, Immunology and Parasitology, Louisiana State University Health Sciences Center, New Orleans, LA 70119, USA and 'Department of Oral

Biology, College of Dentistry, University of Florida, Box 100424, Gainesville, FL 32610, USA

Received: 11 November 2009 Accepted: 14 April 2010

Published: 14 April 2010

\section{References}

1. Jenkinson HF, Lamont RJ: Oral microbial communities in sickness and in health. Trends Microbiol 2005, 13(12):589-595. 
2. Kolenbrander PE, Andersen RN, Blehert DS, Egland PG, Foster JS, Palmer RJ $\mathrm{Jr}$ : Communication among oral bacteria. Microbiol Mol Biol Rev 2002, 66(3):486-505. table of contents

3. Kuramitsu HK, HeX, Lux R, Anderson MH, Shi W: Interspecies interactions within oral microbial communities. Microbiol Mol Biol Rev 2007, 71(4):653-670.

4. Kreth J, Zhang Y, Herzberg MC: Streptococcal antagonism in oral biofilms: Streptococcus sanguinis and Streptococcus gordonii interference with Streptococcus mutans. J Bacteriol 2008, 190(13):4632-4640.

5. Rosan B, Lamont RJ: Dental plaque formation. Microbes Infect 2000, 2(13):1599-1607.

6. Rickard AH, Palmer RJ Jr, Blehert DS, Campagna SR, Semmelhack MF, Egland PG, Bassler BL, Kolenbrander PE: Autoinducer 2: a concentrationdependent signal for mutualistic bacterial biofilm growth. $\mathrm{Mol}$ Microbiol 2006, 60(6):1446-1456.

7. Burne RA: Oral streptococci.products of their environment. J Dent Res 1998, 77(3):445-452

8. Bowen WH, Schilling K, Giertsen E, Pearson S, Lee SF, Bleiweis A, Beeman $D$ : Role of a cell surface-associated protein in adherence and dental caries. Infect Immun 1991, 59(12):4604-4609.

9. Banas JA, Vickerman MM: Glucan-binding proteins of the oral streptococci. Crit Rev Oral Biol Med 2003, 14(2):89-99.

10. Banas JA: Virulence properties of Streptococcus mutans. Front Biosci 2004, 9:1267-1277.

11. Hazlett KR, Mazurkiewicz JE, Banas JA: Inactivation of the gbpA gene of Streptococcus mutans alters structural and functional aspects of plaque biofilm which are compensated by recombination of the gtfB and gtfC genes. Infect Immun 1999, 67(8):3909-3914.

12. Hazlett KR, Michalek SM, Banas JA: Inactivation of the gbpA gene of Streptococcus mutans increases virulence and promotes in vivo accumulation of recombinations between the glucosyltransferase $B$ and C genes. Infect Immun 1998, 66(5):2180-2185.

13. Ooshima T, Matsumura M, Hoshino T, Kawabata S, Sobue S, Fujiwara T: Contributions of three glycosyltransferases to sucrose-dependent adherence of Streptococcus mutans. J Dent Res 2001, 80(7):1672-1677.

14. Tsumori H, Kuramitsu H: The role of the Streptococcus mutans glucosyltransferases in the sucrose-dependent attachment to smooth surfaces: essential role of the GtfC enzyme. Oral Microbiol Immunol 1997, 12(5):274-280.

15. Li YH, Hanna MN, Svensater G, Ellen RP, Cvitkovitch DG: Cell density modulates acid adaptation in Streptococcus mutans: implications for survival in biofilms. J Bacterio/ 2001, 183(23):6875-6884.

16. Li YH, Lau PC, Tang N, Svensater G, Ellen RP, Cvitkovitch DG: Novel TwoComponent Regulatory System Involved in Biofilm Formation and Acid Resistance in Streptococcus mutans. J Bacteriol 2002, 184(22):6333-6342.

17. Li YH, Tang N, Aspiras MB, Lau PC, Lee JH, Ellen RP, Cvitkovitch DG: A quorum-sensing signaling system essential for genetic competence in Streptococcus mutans is involved in biofilm formation. J Bacteriol 2002, 184(10):2699-2708.

18. Wen ZT, Burne RA: LuxS-mediated signaling in Streptococcus mutans is involved in regulation of acid and oxidative stress tolerance and biofilm formation. J Bacterio/ 2004, 186(9):2682-2691.

19. Qi F, Merritt J, Lux R, Shi W: Inactivation of the ciaH Gene in Streptococcus mutans diminishes mutacin production and competence development, alters sucrose-dependent biofilm formation, and reduces stress tolerance. Infect Immun 2004, 72(8):4895-4899.

20. Ahn SJ, Wen ZT, Burne RA: Multilevel control of competence development and stress tolerance in Streptococcus mutans UA159. Infect Immun 2006, 74(3):1631-1642.

21. Suntharalingam P, Senadheera MD, Mair RW, Levesque CM, Cvitkovitch DG: The LiaFSR system regulates the cell envelope stress response in Streptococcus mutans. J Bacteriol 2009, 191(9):2973-2984.

22. Merritt J, Qi F, Goodman SD, Anderson MH, Shi W: Mutation of luxS Affects Biofilm Formation in Streptococcus mutans. Infect Immun 2003, 71(4):1972-1979.

23. Yoshida A, Ansai T, Takehara T, Kuramitsu HK: LuxS-based signaling affects Streptococcus mutans biofilm formation. Appl Environ Microbiol 2005, 71(5):2372-2380.
24. Bassler BL: Small talk. Cell-to-cell communication in bacteria. Cell 2002, 109(4):421-424

25. Wen ZT, Burne RA: Functional genomics approach to identifying genes required for biofilm development by Streptococcus mutans. Appl Environ Microbiol 2002, 68(3):1196-1203.

26. Wen ZT, Baker HV, Burne RA: Influence of BrpA on critical virulence attributes of Streptococcus mutans. J Bacterio/ 2006, 188(8):2983-2992.

27. Loo CY, Corliss DA, Ganeshkumar N: Streptococcus gordonii biofilm formation: identification of genes that code for biofilm phenotypes. $J$ Bacteriol 2000, 182(5):1374-1382.

28. Zeng L, Wen ZT, Burne RA: A novel signal transduction system and feedback loop regulate fructan hydrolase gene expression in Streptococcus mutans. Mol Microbiol 2006, 62(1):187-200.

29. Phan TN, Reidmiller JS, Marquis RE: Sensitization of Actinomyces naeslundii and Streptococcus sanguis in biofilms and suspensions to acid damage by fluoride and other weak acids. Arch Microbiol 2000, 174(4):248-255

30. Wen ZT, Browngardt C, Burne RA: Characterization of two operons that encode components of fructose-specific enzyme II of the sugar:phosphotransferase system of Streptococcus mutans. FEMS Microbiol Lett 2001, 205(2):337-342.

31. Merritt J, Kreth J, Qi F, Sullivan R, Shi W: Non-disruptive, real-time analyses of the metabolic status and viability of Streptococcus mutans cells in response to antimicrobial treatments. J Microbiol Methods 2005, 61(2):161-170

32. Kreth J, Merritt J, Shi W, Qi F: Competition and coexistence between Streptococcus mutans and Streptococcus sanguinis in the dental biofilm. J Bacteriol 2005, 187(21):7193-7203.

33. Shu M, Browngardt CM, Chen YY, Burne RA: Role of urease enzymes in stability of a 10-species oral biofilm consortium cultivated in a constant-depth film fermenter. Infect Immun 2003, 71(12):7188-7192.

34. Sheng J, Marquis RE: Enhanced acid resistance of oral streptococci at lethal $\mathrm{pH}$ values associated with acid-tolerant catabolism and with ATP synthase activity. FEMS Microbiol Lett 2006, 262(1):93-98.

35. Keltjens HM, Schaeken MJ, Hoeven JS van der, Hendriks JC: Microflora of plaque from sound and carious root surfaces. Caries Res 1987 21(3):193-199.

36. Van Houte J, Sansome C, Joshipura K, Kent R: Mutans streptococci and non-mutans streptococci acidogenic at low $\mathrm{pH}$, and in vitro acidogenic potential of dental plaque in two different areas of human dentition. $J$ Dent res 1991, 70:1503-1507.

37. Vacca-Smith AM, Bowen WH: Binding properties of streptococca glucosyltransferases for hydroxyapatite, saliva-coated hydroxyapatite, and bacterial surfaces. Arch Oral Biol 1998, 43(2):103-110.

38. Filoche SK, Anderson SA, Sissons CH: Biofilm growth of Lactobacillus species is promoted by Actinomyces species and Streptococcus mutans. Oral Microbiol Immunol 2004, 19(5):322-326.

39. Li Y, Burne RA: Regulation of the $g t f B C$ and $f t f$ genes of Streptococcus mutans in biofilms in response to $\mathrm{pH}$ and carbohydrate. Microbiol 2001, 147(Pt 10):2841-2848.

40. Hudson MC, Curtiss R: Regulation of expression of Streptococcus mutans genes important to virulence. Infect Immun 1990, 58(2):464-470.

41. Wexler DL, Hudson MC, Burne RA: Streptococcus mutans fructosyltransferase $(f t f)$ and glucosyltransferase ( $g t f B C$ ) operon fusion strains in continuous culture. Infect Immun 1993, 61(4):1259-1267.

42. Nascimento MM, Lemos JA, Abranches J, Lin VK, Burne RA: Role of RelA of Streptococcus mutans in global control of gene expression. J Bacteriol 2008, 190(1):28-36.

43. Bassler BL, Losick R: Bacterially speaking. Cell 2006, 125(2):237-246.

44. McNab R, Ford SK, El-Sabaeny A, Barbieri B, Cook GS, Lamont RJ: LuxSbased signaling in Streptococcus gordonii: autoinducer 2 controls carbohydrate metabolism and biofilm formation with Porphyromonas gingivalis. J Bacterio/ 2003, 185(1):274-284.

45. Lonn-Stensrud J, Petersen FC, Benneche T, Scheie AA: Synthetic bromated furanone inhibits autoinducer-2-mediated communication and biofilm formation in oral streptococci. Oral Microbiol Immunol 2007, 22(5):340-346.

46. Palmer RJ Jr, Kazmerzak K, Hansen MC, Kolenbrander PE: Mutualism versus independence: strategies of mixed-species oral biofilms in vitro 
using saliva as the sole nutrient source. Infect Immun 2001, 69(9):5794-5804.

47. Sztajer H, Lemme A, Vilchez R, Schulz S, Geffers R, Yip CY, Levesque CM, Cvitkovitch DG, Wagner-Dobler I: Autoinducer-2-regulated genes in Streptococcus mutans UA159 and global metabolic effect of the luxS mutation. J Bacterio/ 2008, 190(1):401-415.

48. Wen TZ, Suntharaligham P, Cvitkovitch DG, Burne RA: Trigger factor in Streptococcus mutans is involved in stress tolerance, competence development, and biofilm formation. Infect Immun 2005, 73(1):219-225.

doi: $10.1186 / 1471-2180-10-111$

Cite this article as: Wen et al., Biofilm formation and virulence expression by Streptococcus mutans are altered when grown in dual-species model BMC Microbiology 2010, 10:111

Submit your next manuscript to BioMed Centra and take full advantage of:

- Convenient online submission

- Thorough peer review

- No space constraints or color figure charges

- Immediate publication on acceptance

- Inclusion in PubMed, CAS, Scopus and Google Scholar

- Research which is freely available for redistribution

Submit your manuscript at www.biomedcentral.com/submit 